\title{
Equilibrium Further Studied for Combined System of Cournot and Bertrand: A Differential Approach
}

\author{
Bingyuan Gao $\mathbb{D}^{1,2}$ and Yueping $\mathrm{Du}^{1}$ \\ ${ }^{1}$ School of Economics and Management, Xidian University, Xi'an 710126, China \\ ${ }^{2}$ Department of Economics and Management, Yuncheng University, Yuncheng 044000, China
}

Correspondence should be addressed to Bingyuan Gao; byuang@163.com

Received 27 August 2019; Revised 31 October 2019; Accepted 1 November 2019; Published 27 February 2020

Academic Editor: Quanmin Zhu

Copyright ( 2020 Bingyuan Gao and Yueping Du. This is an open access article distributed under the Creative Commons Attribution License, which permits unrestricted use, distribution, and reproduction in any medium, provided the original work is properly cited.

In general, quantity competition and price competition exist simultaneously in a dynamic economy system. Whether it is quantity competition or price competition, when there are more than three companies in one market, the equilibrium points will become chaotic and are very difficult to be derived. This paper considers generally dynamic equilibrium points of combination of the Bertrand model and Cournot model. We analyze general equilibrium points of the Bertrand model and Cournot model, respectively. A general equilibrium point of the combination of the Cournot model and Bertrand model is further investigated in two cases. The theory of spatial agglomeration and intermediate value theorem are introduced. In addition, the stability of equilibrium points is further illustrated on celestial bodies motion. The results show that at least a general equilibrium point exists in combination of Cournot and Bertrand. Numerical simulations are given to support the research results.

\section{Introduction}

Quantity competition and price competition of oligopoly was debated for many years in an imperfectly competitive market. Some theorists [1-7] pointed out that the competitive equilibrium points, respectively, exist in the Cournot (quantity) model or Bertrand (price) model and compared the equilibrium with each other. Such as Singh and Vives first compared Cournot competition and Bertrand competition.

For quantity equilibrium, the quantity in Cournot competition is larger than that in Bertrand competition in a vertically related duopoly [8]. On the condition that positive network externalities, Pal [9] pointed out that Cournot competition will yield higher profits [10] and prices and lower quantities, welfare [11], and consumers surplus than Bertrand competition. Haraguchi and Matsumura [12] revealed that if the number of companies is five or more, quantity competition may yield a larger profit for each company. Some scholars [1, 13-15] thought that Cournot competition is less efficient than Bertrand competition. Häckner [16] developed Singh and Vives, for more than two companies, and if commodities are complementary, prices may be lower under quantity competition than under price competition. That is called small profit but quick sale in marketing strategy. However, if commodities are substituted, it is beneficial to high-quality companies that they may earn higher profits under price competition than under quantity competition.

For price equilibrium, Vives [17] further pointed out, if the Bertrand equilibrium is unique, then it results are in lower prices than any Cournot equilibrium. Okuguchi [18] compared the equilibrium prices of the Bertrand competition and Cournot oligopolies with product differentiation, and under certain conditions, the Bertrand equilibrium prices are lower than the Cournot ones. Hamilton et al. [19] pointed out, for spatial discrimination of Bertrand competition and Cournot competition, equilibrium prices are lower under Bertrand competition, for low transport costs, profits are higher under Cournot competition, but for larger values of costs, profits are higher under the Bertrand model. The result is contrary to research findings [1].

Motivated from the above, it is not obvious that which kind of competition is more efficient. In reality, quantity competition and price competition exist simultaneously. Both quantity and price treated simultaneously as independent variables are very difficult to analyze. The proof of its uniqueness of the equilibrium point of combination of 
quantity and price becomes more difficult [20]. The equilibrium may be duplicated [21]. As the number of competing companies increases, the equilibrium of quantity and price will present unstable and chaotic phenomenon. A four-oligopoly mixed game of Cournot and Bertrand was detected, which is a complexity and chaotic system and showed the equilibrium point existed [22], and the stability region of the Cournot-Bertrand mixed model is bigger than that of the Cournot model or Bertrand model [23]. When the dynamic system of Bertrand and Cournot becomes stable, only one Nash equilibrium point exists [24]. How to find the general equilibrium points for combination of the Cournot model and Bertrand model is the question we address here.

For equilibrium of competition, some scholars showed the equilibrium results from spatial agglomeration. Such as Hotelling [25]'s linear city model, it concluded that the duopoly companies agglomerate at the center of the line model [26]; however, at center, there exists only a unique location equilibrium. With linear demand in every market of the Cournot game with spatial location choice, the number of companies of the Cournot model is more than two, and there exists a Nash location equilibrium [27]. A unique equilibrium point exists for spatial oligopoly [28]. According to Mayer [29], it appeared that central agglomeration equilibrium only arises in the particular case. d'Aspremont and Thisse [30] modified slightly for the version of Hotelling's example, a price equilibrium solution exists everywhere. Pal and Sarkar [31] pointed out that spatial Cournot competition agglomerates at discrete equilibrium points. Gupta et al. [32] derived the results that an equilibrium exists for agglomeration of companies; however, the only equilibrium exists for agglomeration of duopolists, and a dispersed equilibrium exhibited for duopolists. Matsushima [33] revisited Cournot competition and spatial agglomeration, in a circular city, companies agglomerate at two points. Whether it is price competition or quality competition, many equilibrium points also exist [34], the equilibrium location exhibits spatial agglomeration by pairs [35]. However, the number of equilibrium points is not detected. In equilibrium points, the firms can charge a relative high price, and the prices are randomized [36]. So, it is noteworthy that there are many equilibrium points in oligopoly competition.

In this paper, we further develop Matsushima [33] and Levitan and Shubik [20], explore the general equilibrium points for combination of Bertrand and Cournot from two stages on the basis of spatial agglomeration, and compare with monopoly. The results show that at least a general equilibrium point of combination of Cournot and Bertrand exists. Numerical simulations are given to support the research results.

The paper is organized as follows. Section 2 analyzes the complex dynamical behaviors and general equilibrium point of Cournot competition and Bertrand competition separately and compares the general equilibrium aggregate profits, the general equilibrium price, and the general equilibrium quantity with monopoly. Section 3 takes into account combination of the Cournot model and Bertrand model. The final section concludes the paper.

Notations of selected symbols used in this paper are summarized in Table 1.
TABLE 1: Symbol notation.

\begin{tabular}{lc}
\hline Symbol & Meaning \\
\hline$C_{i}\left(q_{i}\right)$ & Cost function of $i$ company \\
$m_{i}$ & Share of the market \\
$p$ & Price \\
$q$ & Quantity \\
$a, b$ & Parameters of inverse demand function model \\
$\alpha, \beta$ & Parameters of demand function model \\
$q_{m}$ & General equilibrium quantity \\
$p_{m}$ & General equilibrium price \\
$\pi_{m}$ & General equilibrium profit \\
$\pi_{\mathrm{monopoly}}$ & Profit of monopoly \\
$q_{\mathrm{qc}}$ & General equilibrium quantity of combination \\
$p_{\mathrm{qc}}$ & Price of general equilibrium quantity of combination \\
$\pi_{\mathrm{qc}}$ & Profit of general equilibrium quantity of combination \\
$p_{\mathrm{pc}}$ & General equilibrium price of combination \\
$q_{\mathrm{pc}}$ & Quantity of general equilibrium price of combination \\
$\pi_{\mathrm{pc}}$ & Profit of general equilibrium price of combination \\
\hline
\end{tabular}

\section{Model and Analysis}

2.1. Cournot Model. Based on the inverse demand function $p_{i}=a-b Q$ and $Q=q_{1}+q_{2}, i=1,2$, parameter $a>0$ and $b>0$, the dynamic Cournot model can be established. $p_{i}$ is the selling price. $q_{i}(t)$ denotes the quantity of $i$ th company during the period $t=0,1,2, \ldots$. Suppose that the products are identical in a market. The cost function is defined as $C_{i}\left(q_{i}\right)=c_{i} q_{i}^{3}, i=1,2 . c_{i}$ is the industry marginal cost.

Then, the profit of the two companies can be obtained:

$$
\left\{\begin{array}{l}
\Pi_{1}\left(q_{1}, q_{2}\right)=\left(a-b\left(q_{1}+q_{2}\right)\right) q_{1}-c_{1} q_{1}^{3}, \\
\Pi_{2}\left(q_{1}, q_{2}\right)=\left(a-b\left(q_{1}+q_{2}\right)\right) q_{2}-c_{2} q_{2}^{3} .
\end{array}\right.
$$

The $1^{\text {st }}$ company maximizes the profit with respect to $q_{1}$ and the profit of $2^{\text {nd }}$ company with respect to $q_{2}$. The dynamic Cournot model is established:

$$
\left\{\begin{array}{l}
q_{1}(t+1)=a-2 b q_{1}(t)-b q_{2}(t)-3 c_{1} q_{1}^{2}(t), \\
q_{2}(t+1)=a-2 b q_{2}(t)-b q_{1}(t)-3 c_{2} q_{2}^{2}(t) .
\end{array}\right.
$$

The equilibrium points of system (2) is complex. Bifurcation diagrams, attractors, and global maximal Lyapunov exponent [37] are used to show complex dynamical behaviors. The dynamic characteristics of map (2) can be showed by a numerical simulation. It is performed by fixing the parameters of model as follows: $b=0.3, c_{1}=0.1, c_{2}=0.2$, and $0.1<a<2.3$. Criteria for selected parameters is referenced in the literature [38-40]. Figure 1 exhibits the bifurcation diagrams of $q_{1}$ and $q_{2}$ separately with the parameter changing. Figure 2 presents the bifurcation diagram of $q_{1}$ and $q_{2}$. Figure 3 displays the global maximal Lyapunov exponents. It shows that system (2) presents complex behaviors and becomes chaos. The attractor of the system further is explored. Figure 4 shows that the attractor of the system exists. It suggests the existence of deterministic chaotic.

From Figures 1 and 2, there are many Nash equilibrium points in system (2). It is very difficult to derive the number of equilibrium points. 


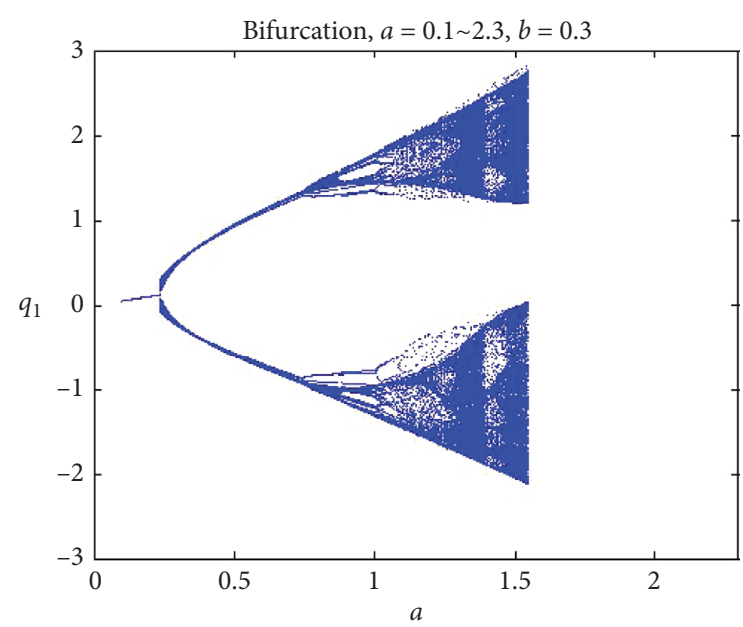

(a)

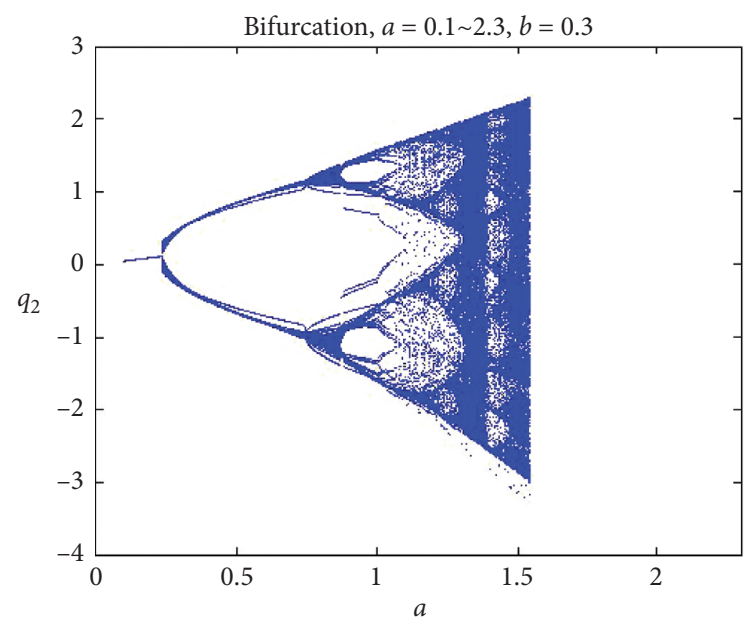

(b)

FIgURE 1: Bifurcation diagrams.

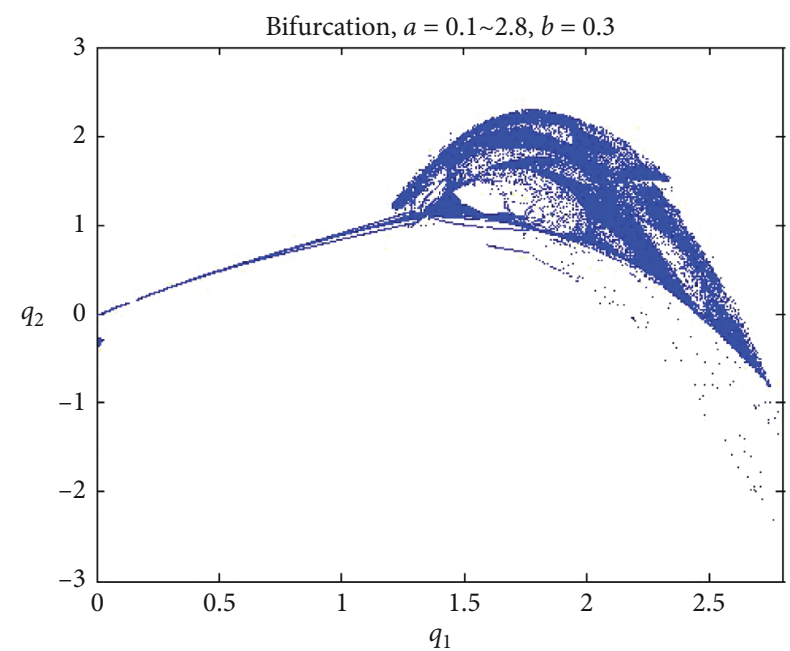

Figure 2: $q_{1}$ and $q_{2}$ bifurcation diagram.

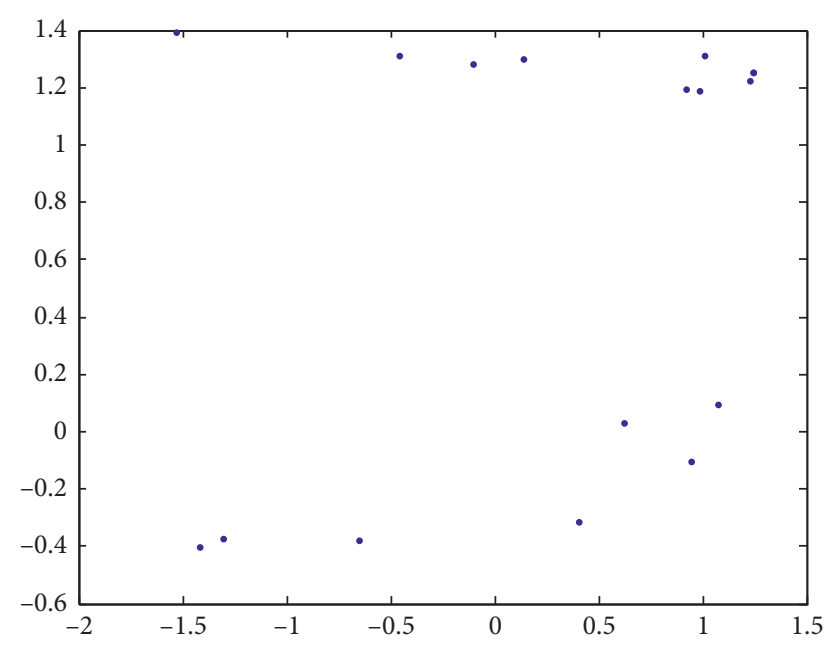

Figure 3: The global maximum Lyapunov exponent.

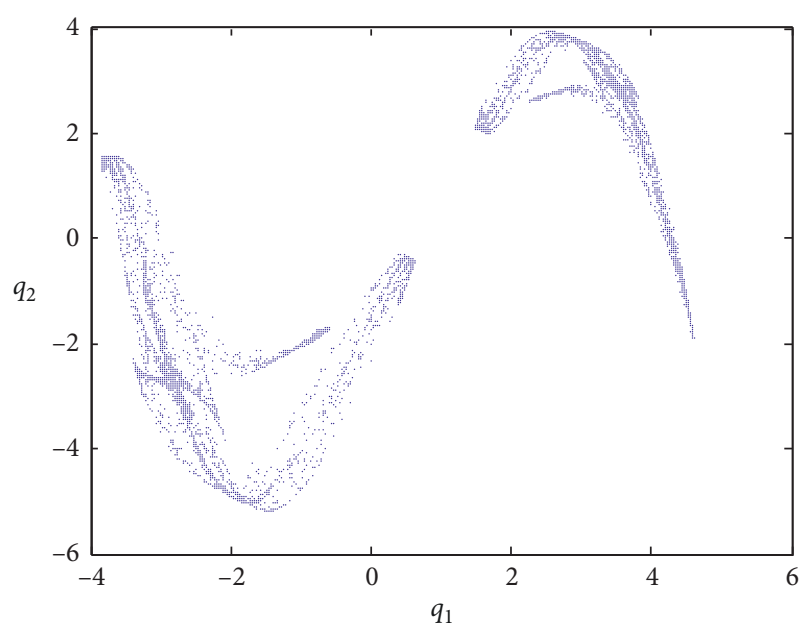

FIgURE 4: $q_{1}$ and $q_{2}$ attractors.

2.2. General Equilibrium Point of Quantity Competition. In duopoly Cournot competition, the dispersion equilibria exists [41], and we can get the inner optional equilibrium output. However, when the number of companies is increasing, the equilibrium points cannot be derived. Gao and $\mathrm{Du}$ [42] further investigated general equilibrium points for the Cournot model. The aggregate production of companies is assumed to be $Q=q_{1}+q_{2}+\cdots+q_{n}$. Their products are identical or similar. If product differentiation is higher, it may destabilize the Nash equilibrium of Cournot [43]. On the identical or similar products, the market price is defined as follows: $P(Q)=P\left(q_{1}+q_{2}+\cdots+q_{n}\right)$. The cost function of any company assumes $C_{i}\left(q_{i}\right), C_{i}\left(q_{i}\right)=c_{i} q_{i}^{j}, i=1,2, \ldots$, $n, j=1 . c_{i}$ is the marginal cost.

The model is expressed as

$$
P\left(q_{j}\right)=a-b \sum_{j=1}^{n} q_{j}, \quad j=1,2, \ldots, n .
$$


The profit of company $i$ can be denoted:

$$
\Pi_{i}\left(q_{1}, q_{2}, \ldots, q_{n}\right)=P\left(q_{1}+q_{2}+\cdots+q_{n}\right) q_{i}-C_{i}\left(q_{i}\right) .
$$

When $i=j=1$, the optimal profit condition of the $i$ th company is satisfied as

$$
f^{\prime}(Q)=f^{\prime}(q)=-2 b q+(a-c)=0,
$$

with parameters

$$
\begin{aligned}
& a>0, \\
& b>0, \\
& a>c .
\end{aligned}
$$

If there exists only a company in one market, the market structure is monopoly. From (5), its production is

$$
q=\frac{a-c}{2 b} \text {. }
$$

Its price is denoted:

$$
p=\frac{a+c}{2}
$$

Its profit can be obtained:

$$
\pi_{\text {monopoly }}=\frac{(a-c)^{2}}{4 b} \text {. }
$$

When $j=n$, the market becomes a perfect competitive market. The quantity can be derived as follows:

$$
q=\frac{a-c}{b} \text {. }
$$

Based on differential Lagrange's intermediate value theorem, from (7) and (10), the general equilibrium quantity of Cournot $q_{m}$ can be derived:

$$
q_{m}=\frac{3(a-c)}{4 b} .
$$

General equilibrium price,

$$
p_{m}=\frac{a+3 c}{4}
$$

General equilibrium profit,

$$
\pi_{m}=\frac{3(a-c)^{2}}{16 b}
$$

Obviously, the value of (9) is greater than that of (13) and the value of (11) is greater than that of (7). It shows that the profit of the monopoly market is the largest than other structures. However, the quantity of monopoly is lower than the general equilibrium quantity. In general, the monopoly company can earn the largest profit by controlling the quantity or price. This is consistent with the reality. When one company intends to enter into one market, the quantity can be estimated by the general equilibrium quantity of the Cournot model. As it is very difficult to get the cost of competitive companies, the average cost can be replaced with the industry average cost.

2.3. Bertrand Model. In the duopoly Bertrand model, based on the demand function $Q=\alpha-\beta\left(p_{1}+p_{2}\right), \alpha>0$ and $\beta>0$, and we can establish a dynamic Bertrand model. $Q$ denotes the quantity. $p_{i}$ is the selling price. $p_{i}(t)$ denotes the price of the $i$ th company during the period $t=0,1,2, \ldots$. Suppose that the products are identical in a market. The cost function is defined as $C_{i}\left(p_{i}\right)=c_{i} Q^{3}, i=1,2 . c_{i}$ is the industry marginal cost.

Then, the profit of the two companies can be obtained:

$$
\left\{\begin{array}{l}
\Pi_{1}=\alpha p_{1}-\beta p_{1}^{2}-\beta p_{1} p_{2}-c_{1} \alpha^{3}+c_{1} \beta^{3}\left(p_{1}+p_{2}\right)^{3}+3 c_{1} \alpha^{2} \beta\left(p_{1}+p_{2}\right)-3 c_{1} \alpha \beta^{2}\left(p_{1}+p_{2}\right)^{2} \\
\Pi_{1}=\alpha p_{2}-\beta p_{2}^{2}-\beta p_{1} p_{2}-c_{2} \alpha^{3}+c_{2} \beta^{3}\left(p_{1}+p_{2}\right)^{3}+3 c_{2} \alpha^{2} \beta\left(p_{1}+p_{2}\right)-3 c_{2} \alpha \beta^{2}\left(p_{1}+p_{2}\right)^{2}
\end{array}\right.
$$

The $1^{\text {st }}$ company maximizes the profit with respect to $p_{1}$ and the profit of $2^{\text {st }}$ company with respect to $p_{2}$. The dynamic Bertrand model is established:

$$
\left\{\begin{array}{l}
p_{1}(t+1)=\alpha-2 \beta p_{1}(t)-\beta p_{2}(t)+3 c_{1} \beta^{3}\left(p_{1}(t)+p_{2}(t)\right)^{2}+3 c_{1} \alpha^{2} \beta-6 c_{1} \alpha \beta^{2}\left(p_{1}(t)+p_{2}(t)\right) \\
p_{2}(t+1)=\alpha-2 \beta p_{2}(t)-\beta p_{1}(t)+3 c_{2} \beta^{3}\left(p_{1}(t)+p_{2}(t)\right)^{2}+3 c_{2} \alpha^{2} \beta-6 c_{2} \alpha \beta^{2}\left(p_{1}(t)+p_{2}(t)\right)
\end{array}\right.
$$

The equilibrium points of system (15) is complex. Bifurcation diagrams, attractors, and global maximal Lyapunov exponent [37] are used to show complex dynamical behaviors. We can see the dynamic characteristics of map (15) by a numerical simulation. It is performed by fixing the parameters of the model as follows: $b=0.328, c_{1}=0.001, c_{2}=0.002$, and $1.1<a<300$. Criteria for selected parameters is referenced in the Cournot model. Figure 5 exhibits the bifurcation diagrams of $p_{1}$ and $p_{2}$ separately with the parameter changing. Figure 6 displays the global maximal Lyapunov exponents. It shows that system (15) presents complex behaviors and becomes chaos. The attractor of the system further is explored. Figure 7 shows that the attractor of the system exists. It suggests the existence of deterministic chaotic. 


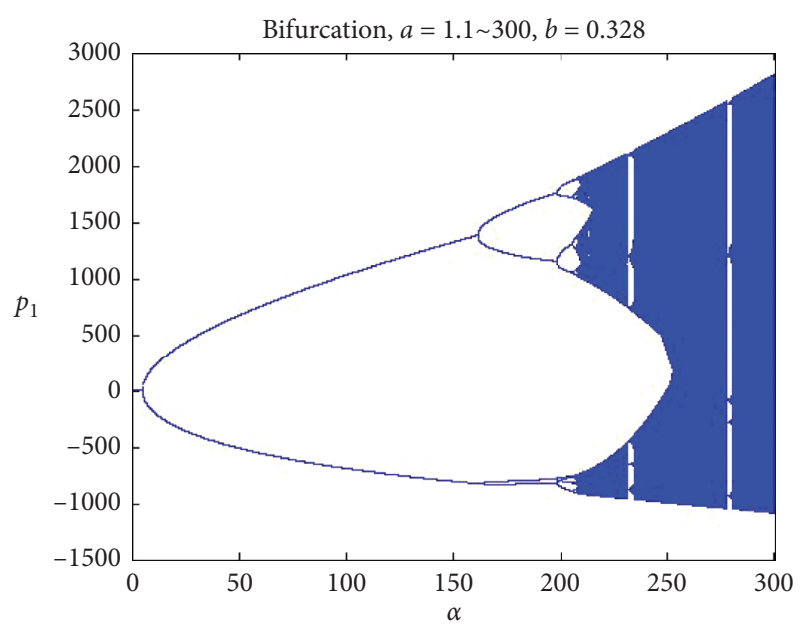

(a)

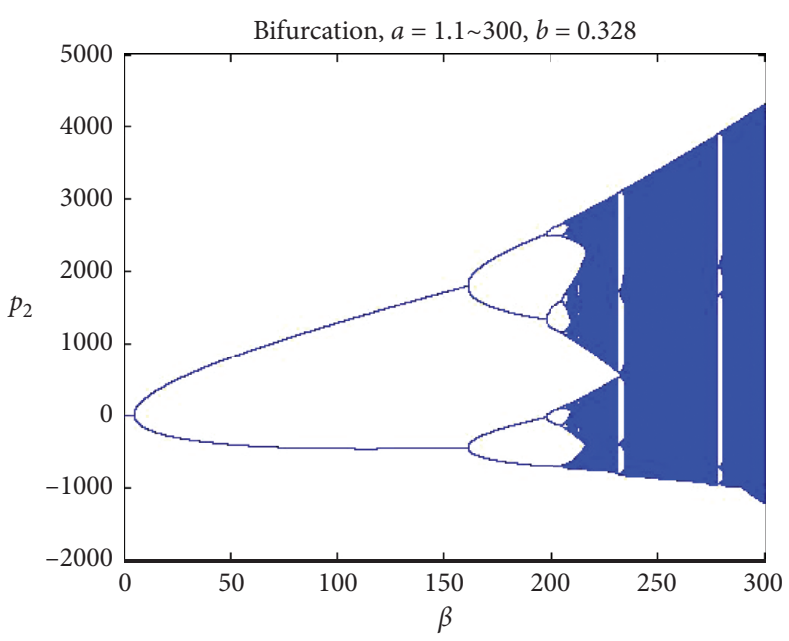

(b)

Figure 5: Bifurcation diagrams.

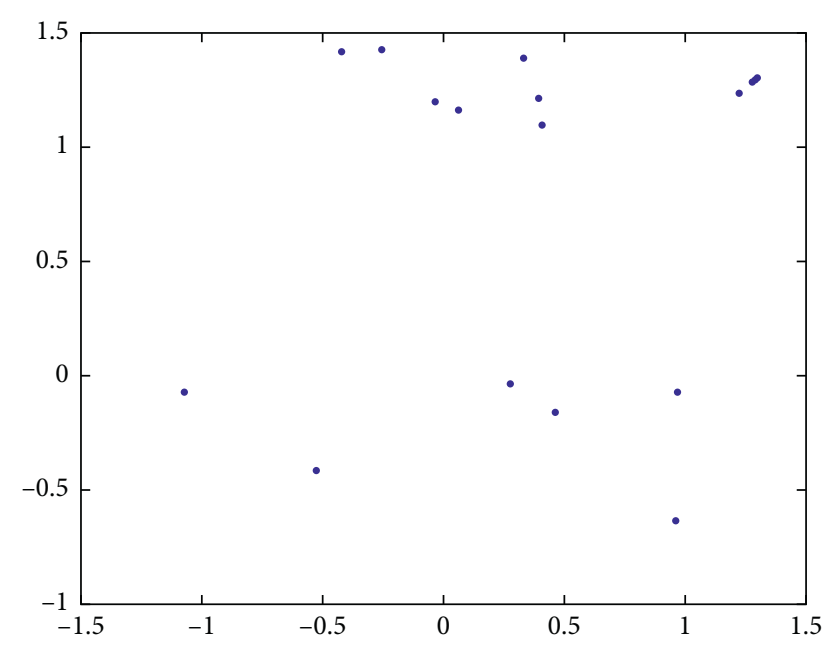

Figure 6: The global maximum Lyapunov exponent.

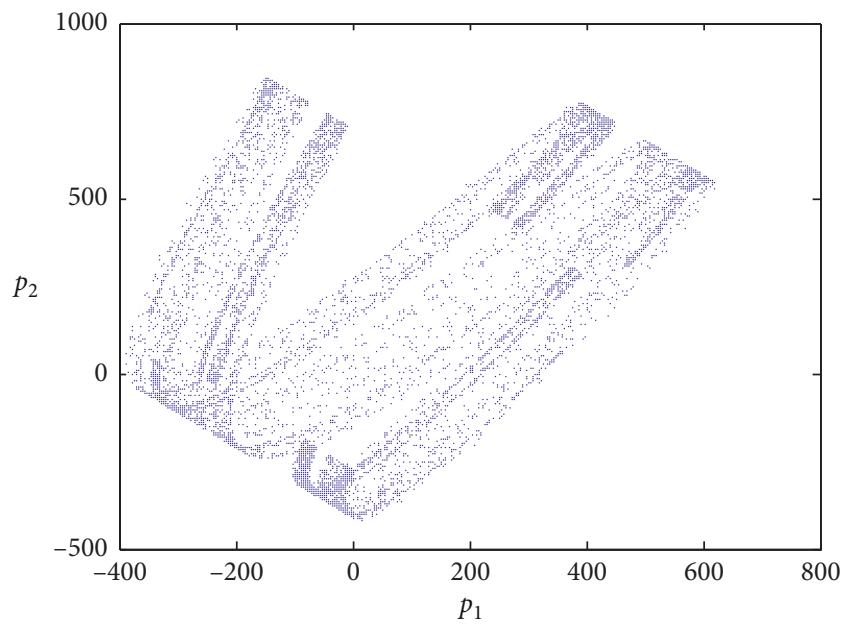

FIgURE $7: p_{1}$ and $p_{2}$ attractors.
From Figure 5, there are many Nash equilibrium points in system (15). However, we cannot derive the equilibrium points so far.

2.4. General Equilibrium Point of Price Competition. The Nash equilibrium of Bertrand becomes unstable as the speed of parameters adjustment increases [44]. In duopoly pricing, it can also produce persistent motion, periodic or chaotic [45]. With the increasing number of companies, the equilibrium points cannot be derived. We expand and develop the previous work of Puu [45]. Now, suppose that there are $n$ companies in a same or similar market. All companies have an identical cost function. The cost can be replaced with the average cost of the industry. In this paper, we focus on oligopoly competition. Without loss of generality, we assume the market demand function:

$$
Q_{i}=\alpha-\beta p_{i}, \quad i=1,2, \ldots, n,
$$

where $Q_{i}$ is the quantity of company $i, \alpha$ and $\beta$ are parameters, and $p$ is the price of product.

All companies produce an identical or similar product. In a certain industry, the total cost function is $C_{i}\left(q_{i}\right), i=$ $1,2, \ldots, n$. As usual in the literature, we assume that all companies have the same cost function, and that the cost function is linear. Therefore, $C(Q)=c Q$. It means that all companies have the same marginal cost and the same average cost and are equal to $c$.

In the monopoly structure, the profit function of a company can be denoted:

$$
R(p)=(p-c) Q=-\beta p^{2}+(\beta c+\alpha) p-\alpha c .
$$

The condition of the inner optimal profit for the monopoly company $i$ is that formula (12) is taken as a partial derivative: 


$$
R^{\prime}(p)=-2 \beta p+\beta c+\alpha .
$$

From formula (17), we may obtain the optimal price:

$$
p=\frac{\beta c+\alpha}{2 \beta}
$$

with parameters

$$
\begin{aligned}
& \alpha>0, \\
& \beta>0, \\
& \alpha>\beta c .
\end{aligned}
$$

In a perfectly competitive structure market, the price is equal to the average cost (marginal cost):

$$
p=c \text {. }
$$

With the development of economy, the congeneric market will become more and more stable, and the equilibrium of competition will result in aggregation. A spatial aggregation concept model is built to illuminate imperfectly competitive equilibrium. That is to say, Bertrand competition is an imperfect competition. Now, we define $p_{m}$ as a general equilibrium price that we will seek for. The region between $u$ and $v$ is the chaotic district of the Bertrand model when there are $n$ companies in the congeneric market, such as Figure 8.

The $u$ endpoint represents the monopoly market, and the $v$ endpoint is the perfectly competitive market.

Suppose 1. Based on the differential Lagrange's intermediate value theorem, there exists some $z$ points on the open interval $(u, v)$ (where $(u<v)$ ). Let function $f$ : $[u, v] \longrightarrow R$ be a continuous function on the closed interval $[u, v]$ and differentiable on the open interval $(u, v)$. The derivative of function $f$ at $z$ equals the difference quotient $\Delta f(u, v)$. That is to say, there exists a point $z$ in $(u, v)$, such that

$$
\triangle f(u, v)=f^{\prime}(z)=\frac{f(v)-f(u)}{v-u},
$$

$p_{m}$ is one of the salient points of the Bertrand model. We can derive $p_{m}$ on the intermediate value theorem. Suppose 2. The endpoint $u=(\alpha+\beta c) / 2 \beta$, and the other endpoint $v=c$.

On the closed interval $[(\alpha+\beta c) / 2 \beta, c]$,

$$
f^{\prime}(z)=f^{\prime}\left(p_{m}\right)=\frac{f(v)-f(u)}{v-u}=\frac{\alpha-\beta c}{2} .
$$

Substituting (23) back into (18) yields finally, we can get at least a general equilibrium point of price in the Bertrand model:

$$
p_{m}=\frac{3 \beta c+\alpha}{4 \beta} \text {. }
$$

By a numerical simulation, in order to test the stability of results, without loss of generality, fix the parameters $c=2$, $2<\alpha<3$, and $1<\beta<2$. From Figure 9, the distribution state of $p_{m}$ is a complex surface. The surface is composed of a set

$$
p_{m}
$$

\section{FIGURE 8: Price spatial aggregation model.}

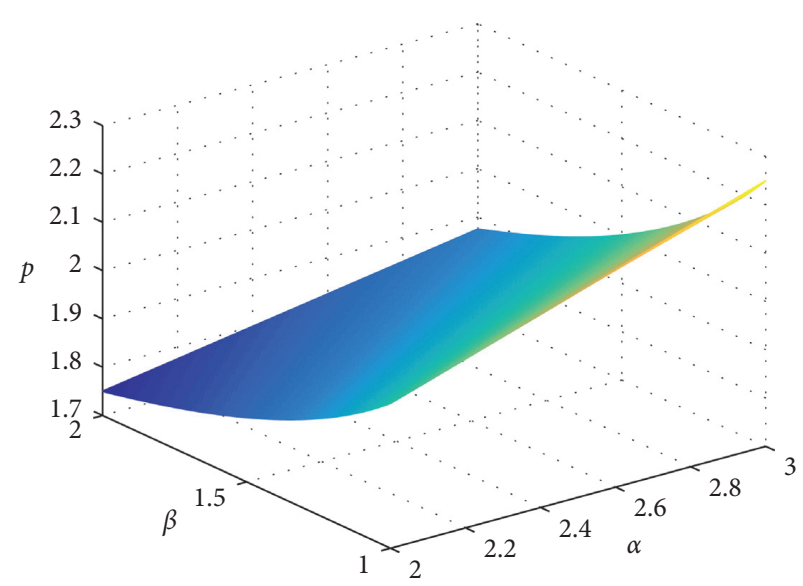

Figure 9: $p_{m}$ distribution state $c=2,2<\alpha<3$, and $1<\beta<2$.

of solutions, and it is a lower convex surface. The convex surface is also called an attractor. In general, the attractor of the value of $p_{m}$ is stable. Simulation result demonstrates the validity and stability of the new algorithm. That is to say, a convex point exists in the Bertrand model. At least, an equilibrium point $p_{m}$ is derived between the monopoly market structure and perfect market structure. However, with the increasing number of companies, it will not become unstable.

From (16) and (24), we can derive general equilibrium quantity:

$$
q_{m}=\frac{3(\alpha-\beta c)}{4} .
$$

From (17), (24), and (25), the general equilibrium profit of Bertrand is derived:

$$
\pi_{m}=\frac{3(\alpha-\beta c)^{2}}{16 \beta} .
$$

When there is only a company in the market, the company is a monopoly. The price is expressed as

$$
p=\frac{\beta c+\alpha}{2 \beta} \text {. }
$$

Its production is denoted:

$$
q=\frac{\alpha-\beta c}{2} \text {. }
$$

The profit of the monopoly is denoted:

$$
\pi_{\text {monopoly }}=\frac{(\alpha-\beta c)^{2}}{4 \beta} \text {. }
$$

From above, we can conclude that the value of (23) is larger than that of (24), and the value of (29) is also larger 
than that of (26). It shows that the competition of the Bertrand can cause lower general equilibrium price than monopoly competition. The result is not the same as that of [46], which showed the competition of Bertrand's model can yield higher prices than monopoly. The profit of Bertrand's model is also lower than monopoly. It is clear that the general equilibrium profit of Bertrand's model is not better than monopoly. However, at least a general equilibrium point of the Bertrand model is derived. In the imperfectly competitive market, the company can obtain optimal profit by the general equilibrium price.

\section{General Equilibrium of Combination of Quantity and Price}

In practise, both price competition and quantity competition exists simultaneously in competitive markets. According to Vernon [47], there are three stages in a product life cycle: introduction, maturity, and standardized stage. Monopoly is in the stage of location of new products. The competition of Cournot and that of Bertrand locate in two other stages. Such as in Figure 10, with the constant dynamic competition of companies, quantity competition and price competition will stabilize. This situation is located in the maturity stage and standardized stage. Obviously, quantity competition and price competition exist and are applied simultaneously for company competition in the maturity stage and standardized stage. This paper built a dynamic aggregation game model of two stage to detect the general equilibrium point of combination of quantity competition and price competition based on the general equilibrium point of quantity competition and general equilibrium point of price competition, respectively. In the first stage, quantity competition is the dominant competitive strategy with price competition. It is debated that whether or not an equilibrium point of quantity competition exists in combination of quantity competition and price competition. In the second stage, price competition is the dominant competitive strategy with quantity competition, and a general competitive equilibrium point of price will also be explored.

\subsection{General Competitive Equilibrium of Dominant Quantity}

Define 1. $q_{\mathrm{qc}}$ is the general equilibrium point of dominant quantity competition with price competition.

In this stage, many companies compete mainly by quantity. The more products the companies produce, the more competitive it becomes. It must result in low price. However, the profit is sometimes not better. If the company produces less, unless the product is priced high, the profit is also less. Other companies compete with each other by price. In this economic system with quantity competition and price competition, it becomes more significant to find general equilibrium quantity for combination of quantity and price. It can help companies to obtain better profit.

From Section 2, based on the differential Lagrange's intermediate value theorem, we define the endpoint $u=$ $3(a-c) / 4 b$ and other endpoint $v=3(\alpha-\beta c) / 4$ :

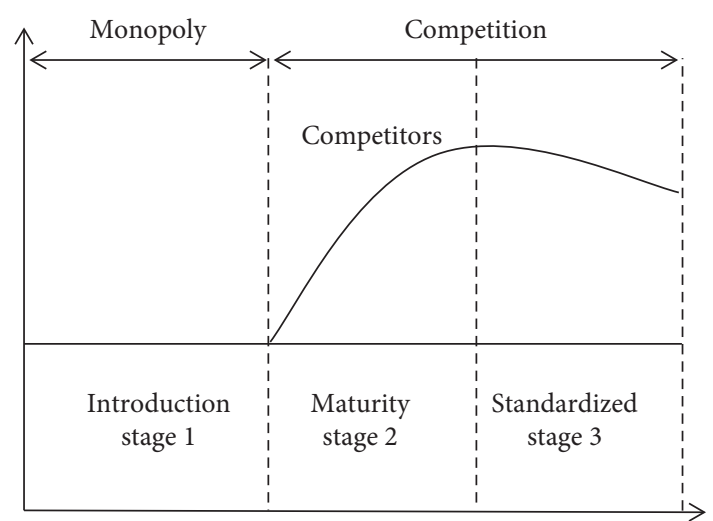

Figure 10: Product life cycle.

$$
f^{\prime}\left(q_{\mathrm{qc}}\right)=\frac{3 b^{2}(\alpha-\beta c)^{2}-4 b(a-c)(\alpha-\beta c)-8(a-c)^{2}}{4(a-c)-4 b(\alpha-\beta c)} .
$$

On the open interval $(3(a-c) / 4 b, 3(\alpha-\beta c) / 4)$, from (3) and (25), the general equilibrium quantity $q_{\mathrm{qc}}$ of combination of quantity and price can be derived:

$$
q_{\mathrm{qc}}=\frac{12(a-c)^{2}-3 b^{2}(\alpha-\beta c)^{2}}{8 b(a-c)-8 b^{2}(\alpha-\beta c)} .
$$

Figures 11 and 12 show that the distribution of $q_{\mathrm{qc}}$ is a complex surface. The surface is called the attractor in the chaotic system. We change the values of parameter $\alpha, \beta, a$, and $b$, the results have no effect on the distribution of $q_{\mathrm{qc}}$ value. It shows that the value of $q_{\mathrm{qc}}$ is stable. Based on the three-body problem in the space, the oligarch companies will gather with a dynamic economic system. The solutions of the system are dynamic and stable. Therefore, the value of $q_{\mathrm{qc}}$ is fixed and stable. That is to say, a convex equilibrium point of quantity exists in the model of combination of quantity and price. It is clear that at least a general equilibrium point $q_{\mathrm{qc}}$ can be derived for combination of Bertrand and Cournot.

The equilibrium price $p_{\mathrm{qc}}$ also is derived on inverse demand function:

$$
p_{\mathrm{qc}}=a-\frac{12(a-c)^{2}-3 b^{2}(\alpha-\beta c)^{2}}{8(a-c)-8 b(\alpha-\beta c)} .
$$

The equilibrium profit $\pi_{\mathrm{qc}}$ is denoted:

$$
\pi_{\mathrm{qc}}=\frac{3 b^{2}(\alpha-\beta c)^{2}-4(a-c)^{2}-8 b(a-c)(\alpha-\beta c)}{b(8(a-c)-8 b(\alpha-\beta c))^{2}} .
$$

By comparing the value of (7) and that of (31) and the value of (9) and that of (33), it is obviously that the profit of the monopoly is the biggest. However, the quantity of monopoly is smaller than that of combination of quantity and price.

3.2. General Competitive Equilibrium of Dominant Price. Now, we will further explore the general equilibrium price in combination of Bertrand and Cournot for $n$ companies. In this stage, many companies compete mainly by price. If the 


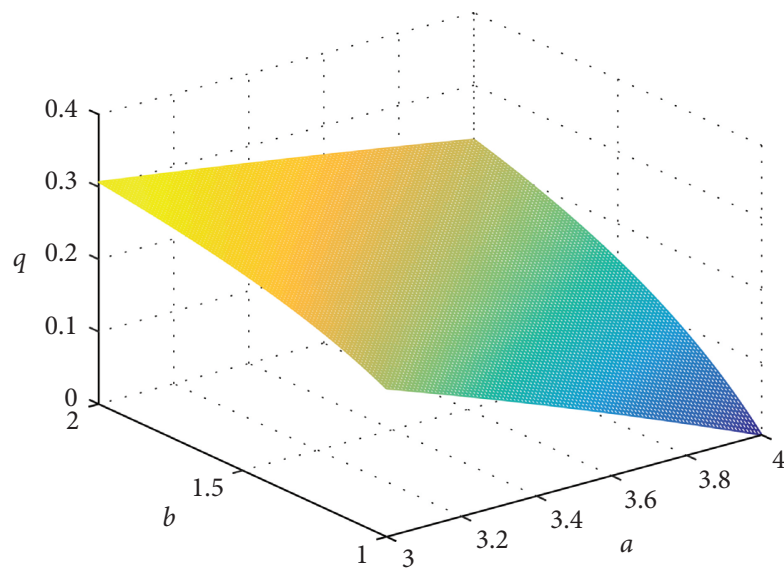

(a)

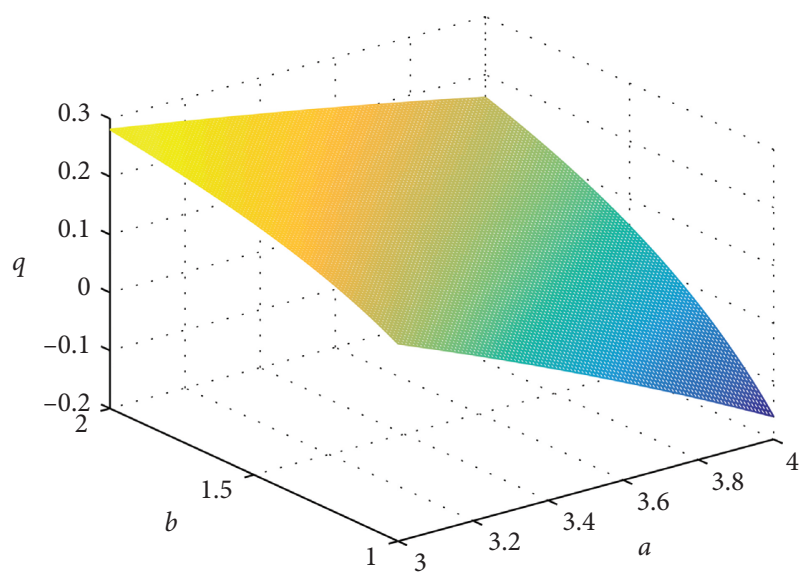

(b)

Figure 11: $q_{\mathrm{qc}}$ distribution state. (a) $c=2, \alpha=12, \beta=2,3<a<4$, and $1<b<2$ and (b) $c=2, \alpha=12, \beta=3,3<a<4$, and $1<b<2$.

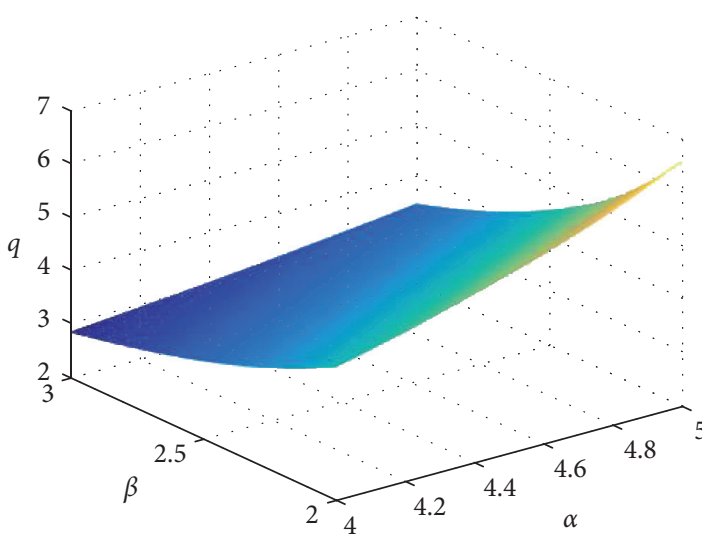

(a)

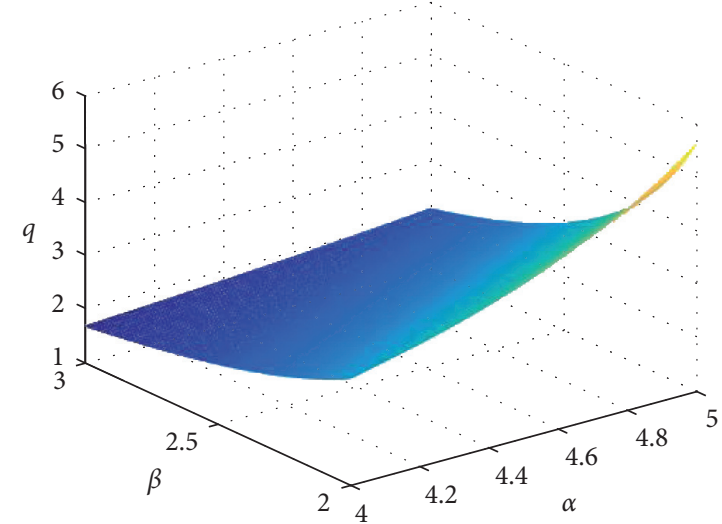

(b)

FIgURE 12: $q_{\mathrm{qc}}$ distribution state. (a) $c=2, a=5, b=1,3<\alpha<4$, and $1<\beta<2$ and (b) $c=2, a=8, b=3,3<\alpha<4$, and $1<\beta<2$.

product is priced lower, companies will make less profit. If the product is priced higher, the sales will fall. To be corresponding to this, other companies compete by quantity. Whether it is price competition or quantity competition, maximizing profit is the goal of any company. From Section 2 , with the intermediate value theorem, the general equilibrium price of combination of quantity and price may be detected. It can maximize the companies' profit.

Define 2. $p_{\mathrm{pc}}$ is general equilibrium of dominant price with quantity competition.

Based on the differential Lagrange's intermediate value theorem, we suppose the end $u=(3 \beta c+\alpha) / 4 \beta$ and the other end $v=(3 c+a) / 4$. On the open interval $((3 \beta c+\alpha) / 4 \beta$, $(3 c+a) / 4)$,

$$
f^{\prime}\left(p_{\mathrm{pc}}\right)=\frac{\beta(a+3 c)(a \beta-4 \alpha-\beta c)+(3 \beta c+\alpha)(\beta c+3 \alpha)}{4(\alpha-a \beta)} .
$$

Here, assume $a=\alpha$, and formula (29) is also expressed as (30):

$$
f^{\prime}\left(p_{\mathrm{pc}}\right)=\frac{3 \alpha^{2}+4 \alpha^{2} \beta^{2}-4 \alpha^{2} \beta-\alpha \beta^{2} c-3 \alpha \beta c}{4 \alpha(1-\beta)}
$$

From (13) and (30), $p_{\mathrm{pc}}$ can be derived:

$$
p_{\mathrm{pc}}=\frac{\alpha+7 \beta c-3 \beta^{2} c-4 \alpha \beta^{2}}{8 \beta(1-\beta)} .
$$

From Figure 13, the state of $p_{\mathrm{pc}}$ is a complex convex surface by a number simulation. Based on the solution of the three-body problem, the surface exists attractor, the value of $p_{\mathrm{pc}}$ is also stable. The solution set forms a lower convex surface. It is obvious that a convex equilibrium point of price exists in the model of combination of quantity and price. We find the equilibrium point $p_{\mathrm{pc}}$ in the combination of Bertrand and Cournot. If a company will enter into a relative market by price strategy, the result can offer a method to estimate the equilibrium price of the market.

Here, assume $r=\alpha+7 \beta c-3 \beta^{2} c-4 \alpha \beta^{2}$, and formula (31) is also expressed as (32): 


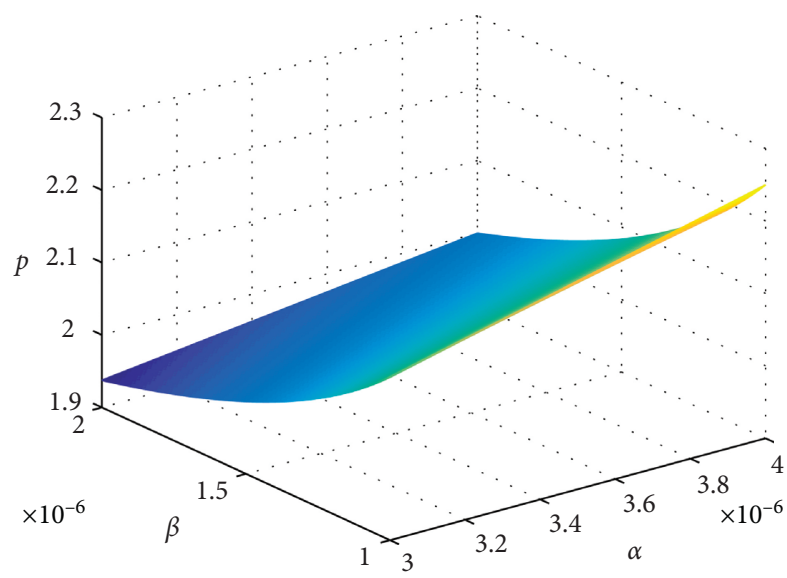

Figure 13: $p_{\mathrm{pc}}$ distribution state $c=2,3 \times 10^{-6}<\alpha<4 \times 10^{-6}$ and $1 \times 10^{-6}<\beta<2 \times 10^{-6}$.

$$
p_{\mathrm{pc}}=\frac{r}{8 \beta(1-\beta)}
$$

with $p_{\mathrm{pc}}$ and demand function, equilibrium quantity $q_{\mathrm{pc}}$ can be derived:

$$
q_{\mathrm{pc}}=\alpha-\frac{r}{8(1-\beta)}
$$

Then, we can calculate the equilibrium profit:

$$
\pi_{\mathrm{pc}}=\frac{(r-8 c \beta(1-\beta))(8 \alpha(1-\beta)-r)}{64 \beta(1-\beta)^{2}} .
$$

We compare the value of (37) and that of (20). The result shows that the value of (37) is bigger than that of (20). The result is consistent with [35]. The price of monopoly is lower than the general equilibrium price of combination of quantity and price. By complex processing, the value of (39) is relatively small than that of (26). The result shows that the profit of monopoly is the best profit. Thus, it can be seen that the monopoly company can also earn huge profits by low price.

\section{Concluding Remarks}

This paper provides additional information about general equilibrium of oligopoly of combination of price and quantity. We separately derive the general equilibrium quantity of combination of quantity and price and the general equilibrium price of combination of quantity and price. The general equilibrium quantity of combination is derived with the general equilibrium quantity of the Cournot model and the general equilibrium quantity of the Bertrand model. The general equilibrium price of combination is derived with the general equilibrium price of the Bertrand model and the general equilibrium price of the Cournot model. Intermediate value theorem is introduced to handle the problem of general equilibrium. The results show that the general equilibrium points of combination of the Cournot model and Bertrand model exist. We construct the space aggregation model to illustrate economic connotation of the market structure. In the three-dimensional dynamic economic system, the distributing of $p_{m}, q_{\mathrm{qc}}$, and $p_{\mathrm{pc}}$ is a complex surface, respectively. The surface is called the attractor and it is stable. It means that these general equilibrium points are stable. Numerical simulations are given to support the research results.

The results show that no matter which market structure it is, the profit of monopoly is the biggest. However, some previous studies compared the Bertrand equilibrium prices with the Cournot equilibrium price under the same market structure. Such as $[18,19]$, the results show that the Bertrand equilibrium prices are lower than the Cournot ones. Other [10] results show that Cournot competition can yield lower quantities than Bertrand competition. However, in this paper, we compare the general Cournot's equilibrium quantity with that of monopoly and the general Bertrand's equilibrium price with that of monopoly. It is significant that the general equilibrium price of combination of quantity and price can generate higher price than monopoly. By contrast, the general equilibrium quantity of combination of quantity and price can also generate higher quantity than monopoly.

This paper provides a theoretical foundation on how to make the company itself to obtain the optimal quantity strategy or the optimal price strategy. In a dynamic economy system, when a company is about to enter into a relative market, according to the industry marginal cost (the average cost), the demand function, inverse demand function of a competitive company, the general equilibrium quantity of combination, and general equilibrium price of combination can be separately calculated.

\section{Data Availability}

The authors declare that no data were used to support this study.

\section{Conflicts of Interest}

No conflicts of interest for all authors.

\section{Acknowledgments}

This work was supported in part by the Program for the Philosophy and Social Sciences Research of Higher Learning Institutions of Shanxi (CN) (2019W158).

\section{References}

[1] N. Singh and X. Vives, "Price and quantity competition in a differentiated duopoly," The RAND Journal of Economics, vol. 15 , no. 4, pp. 546-554, 1984.

[2] L. Cheng, "Comparing bertrand and cournot equilibria: a geometric approach," The RAND Journal of Economics, vol. 16, no. 1, pp. 146-152, 1985.

[3] S. S. Askar, M. F. El-Wakeel, and M. A. Alrodaini, "Exploration of complex dynamics for cournot oligopoly game with differentiated products," Complexity, vol. 2018, Article ID 6526794, 13 pages, 2018.

[4] J. Ma, L. Sun, and X. Zhan, "Study on triopoly dynamic game model based on different demand forecast methods in the market," Complexity, vol. 2017, Article ID 5434680, 12 pages, 2017. 
[5] L. Zhao, "Nonlinear complex dynamics of carbon emission reduction cournot game with bounded rationality," Complexity, vol. 2017, Article ID 8301630, 10 pages, 2017.

[6] P. J. Graber and A. Bensoussan, "Existence and uniqueness of solutions for Bertrand and cournot mean field games," $A p$ plied Mathematics \& Optimization, vol. 77, no. 1, pp. 47-71, 2016.

[7] A. Bensoussan, K. C. J. Sung, S. C. P. Yam, and S. P. Yung, "Linear-quadratic mean field games," Journal of Optimization Theory and Applications, vol. 169, no. 2, pp. 496-529, 2016.

[8] D. J. Lee and J. Oh, "Price versus quantity competition with asymmetric costs in a vertically related duopoly," in Proceedings of the 2014 Joint 7th International Conference on Soft Computing and Intelligent Systems (SCIS) and 15th International Symposium on Advanced Intelligent Systems (ISIS), Kitakyushu, Japan, December 2014.

[9] R. Pal, "Cournot vs. Bertrand under relative performance delegation: implications of positive and negative network externalities," Mathematical Social Sciences, vol. 75, pp. 94101, 2015.

[10] X. Diao, Y. Deli, and L. Zhengkui, "Competitive strategies of product with vertical differentiation," in Proceedings of the 2008 International Conference on Information Management, Innovation Management and Industrial Engineering, Taipei, Taiwan, December 2008.

[11] W.-J. Liang, H. Hwang, and C.-C. Mai, "Spatial discrimination: Bertrand vs. Cournot with asymmetric demands," Regional Science and Urban Economics, vol. 36, no. 6, pp. 790-802, 2006.

[12] J. Haraguchi and T. Matsumura, "Cournot-Bertrand comparison in a mixed oligopoly," Journal of Economics, vol. 117, no. 2, pp. 117-136, 2015.

[13] M. Alipranti, C. Milliou, and E. Petrakis, "Price vs. quantity competition in a vertically related market," Economics Letters, vol. 124, no. 1, pp. 122-126, 2014.

[14] R. Amir and J. Y. Jin, "Cournot and Bertrand equilibria compared: substitutability, complementarity and concavity," International Journal of Industrial Organization, vol. 19, no. 34, pp. 303-317, 2001.

[15] L. Cheng, Bertrand Equilibrium Is More Competitive than Cournot Equilibrium: The Case of Differentiated Products, Mimeo, University of Florida, Gainesville, FL, USA, 1984.

[16] J. Häckner, "A note on price and quantity competition in differentiated oligopolies," Journal of Economic Theory, vol. 93, no. 2, pp. 233-239, 2000.

[17] X. Vives, "On the efficiency of Bertrand and Cournot equilibria with product differentation," Journal of Economic Theory, vol. 36, no. 1, pp. 166-175, 1985.

[18] K. Okuguchi, "Equilibrium prices in the Bertrand and Cournot oligopolies," Journal of Economic Theory, vol. 42, no. 1, pp. 128-139, 1987.

[19] J. H. Hamilton, J.-F. Thisse, and A. Weskamp, "Spatial discrimination: Bertrand vs. Cournot in a model of location choice," Regional Science and Urban Economics, vol. 19, no. 1, pp. 87-102, 1989.

[20] R. Levitan and M. Shubik, "Duopoly with price and quantity as strategic variables," International Journal of Game Theory, vol. 7, no. 1, pp. 1-11, 1978.

[21] D. J. Lee, "Can we duplicate a sequential game with an asymmetric simultaneous game," in Proceedings of the 2016 Joint 8th International Conference on Soft Computing and Intelligent Systems (SCIS) and 17th International Symposium on Advanced Intelligent Systems (ISIS), pp. 113-117, Sapporo, Japan, August 2016.
[22] J. Ma and L. Sun, "Complexity analysis about nonlinear mixed oligopolies game based on production cooperation," IEEE Transactions on Control Systems Technology, vol. 26, no. 4, pp. 1532-1539, 2018.

[23] H. Wang and J. Ma, "Complexity analysis of a CournotBertrand duopoly game with different expectations," Nonlinear Dynamics, vol. 78, no. 4, pp. 2759-2768, 2014.

[24] J. Ma and X. Pu, "The research on Cournot-Bertrand duopoly model with heterogeneous goods and its complex characteristics," Nonlinear Dynamics, vol. 72, no. 4, pp. 895-903, 2013.

[25] H. Hotelling, "Stability in competition," The Economic Journal, vol. 39, no. 153, pp. 41-57, 1929.

[26] D. Pal, "Does cournot competition yield spatial agglomeration?," Economics Letters, vol. 60, no. 1, pp. 49-53, 1998.

[27] J. Sarkar, B. Gupta, and D. Pal, "Location equilibrium for cournot oligopoly in spatially separated markets," Journal of Regional Science, vol. 37, no. 2, pp. 195-212, 2010.

[28] M. J. Beckmann, "Spatial oligopoly as a noncooperative game," International Journal of Game Theory, vol. 2, no. 1, pp. 263-268, 1973.

[29] T. Mayer, "Spatial Cournot competition and heterogeneous production costs across locations," Regional Science and Urban Economics, vol. 30, no. 3, pp. 325-352, 1999.

[30] C. d'Aspremont and G. F. Thisse, "On hotelling's "stability in competition"," Econometrica, vol. 47, no. 5, pp. 1145-1150, 1979.

[31] D. Pal and J. Sarkar, "Spatial competition among multi-store firms," International Journal of Industrial Organization, vol. 20, no. 2, pp. 163-190, 2002.

[32] B. Gupta, D. Pal, and J. Sarkar, "Spatial Cournot competition and agglomeration in a model of location choice," Regional Science and Urban Economics, vol. 27, no. 3, pp. 261-282, 1997.

[33] N. Matsushima, "Cournot competition and spatial agglomeration revisited," Economics Letters, vol. 73, no. 2, pp. 175177, 2001.

[34] C.-M. Yu, "Price and quantity competition yield the same location equilibria in a circular market," Papers in Regional Science, vol. 86, no. 4, pp. 643-655, 2010.

[35] C.-M. Yu and F.-C. Lai, "Cournot competition in spatial markets: some further results," Papers in Regional Science, vol. 82, no. 4, pp. 569-580, 2003.

[36] M. J. Osborne and C. Pitchik, "Equilibrium in hotelling's model of spatial competition," Econometrica, vol. 55, no. 4, pp. 911-922, 1987.

[37] P. Balenzuela and C. O. Dorso, "Maximum Lyapunov exponent of highly excited finite systems," Physica A, vol. 283, no. 1-2, pp. 267-272, 2000.

[38] S. S. Askar and M. F. Elettreby, "The impact of cost uncertainty on Cournot oligopoly games," Applied Mathematics and Computation, vol. 312, pp. 169-176, 2017.

[39] L. Chen and G. Chen, "Controlling chaos in an economic model," Physica A: Statistical Mechanics and Its Applications, vol. 374, no. 1, pp. 349-358, 2007.

[40] Z. Ding, Q. Wang, and S. Jiang, "Analysis on the dynamics of a Cournot investment game with bounded rationality," Economic Modelling, vol. 39, pp. 204-212, 2014.

[41] C. Benassi, "Dispersion equilibria in spatial Cournot competition," The Annals of Regional Science, vol. 52, no. 2, pp. 611-625, 2014.

[42] B. Gao and Y. Du, "Exploring general equilibrium points for cournot model," Discrete Dynamics in Nature and Society, vol. 2018, Article ID 7630395, 7 pages, 2018. 
[43] A. Agliari, A. K. Naimzada, and N. Pecora, "Nonlinear dynamics of a Cournot duopoly game with differentiated products," Applied Mathematics and Computation, vol. 281, pp. 1-15, 2016.

[44] E. Ahmed, A. A. Elsadany, and T. Puu, "On Bertrand duopoly game with differentiated goods," Applied Mathematics and Computation, vol. 251, pp. 169-179, 2015.

[45] T. Puu, "Chaos in duopoly pricing," Chaos, Solitons \& Fractals, vol. 1, no. 6, pp. 573-581, 1991.

[46] H. Sanner, "Bertrand competition can yield higher prices than monopoly," Bulletin of Economic Research, vol. 59, no. 3, pp. 247-254, 2007.

[47] R. Vernon, "International investment and international trade in the product cycle," The International Executive, vol. 8, no. 4, p. 16, 1966. 